\title{
Hypoxic-Ischemic Encephalopathy: Impact on Retinal Neurovascular Integrity and Function
}

\author{
Ismail S. Zaitoun ${ }^{1,2}$, PhD; Nader Sheibani ${ }^{1,2,3,4}$, PhD \\ ${ }^{1}$ Department of Ophthalmology and Visual Sciences, University of Wisconsin School of Medicine and Public Health, Madison, \\ WI, USA \\ ${ }^{2}$ McPherson Eye Research Institute, University of Wisconsin School of Medicine and Public Health, Madison, WI, USA \\ ${ }^{3}$ Department of Cell and Regenerative Biology, University of Wisconsin School of Medicine and Public Health, Madison, WI, USA \\ ${ }^{4}$ Department of Biomedical Engineering, University of Wisconsin School of Medicine and Public Health, Madison, WI, USA \\ ORCID: \\ Ismail Zaitoun: https://orcid.org/0000-0001-7174-5403 \\ Nader Sheibani: https://orcid.org/0000-0003-2723-9217
}

J Ophthalmic Vis Res 2021; 16 (3): 317-319

Hypoxic-ischemic encephalopathy (HIE) along with its impact on vision has been recognized for some time. HIE, one of the most common brain injuries, results from secondary oxygen deprivation and blood flow reduction to the brain. Its incidence ranges from 1 to 8 per 1,000 live births in developed countries. ${ }^{[1]} \mathrm{A}$ considerable proportion of HIE patients display visual impairment, ${ }^{[2,3]}$ which was considered to be solely due to lesions in the brain neural visual structures and processing. ${ }^{[4]}$ Although recent preclinical studies suggest a direct impact on the retinal visual function, the underlying mechanisms and the retinal cells targeted and affected in response to HIE remain unknown.

The preclinical Rice-Vannucci model is a frequently used acute HIE model in mouse and rat pups. ${ }^{[5-9]}$ This hypoxic-ischemic model is attained by constant occlusion of only one of the common carotid arteries (CCA) followed by exposure of the animal to an air mixture with low oxygen. Exposure to these conditions results in brain damage specific to the hemisphere on the side of the ligated CCA. ${ }^{[10]}$ The CCA provides blood supply to the ophthalmic artery that renders the eye susceptible to HIE insult. This model is frequently used to study the effect of HIE on structural and functional integrity of the brain. In addition, this model has been used to demonstrate the damaging effect of the HIE on the blood vessels ${ }^{[11]}$ or the neurons ${ }^{[12,13]}$ of the rat retina. The development and homeostasis of both the neuronal and the vascular systems are interconnected. ${ }^{[14]}$

To the best of our knowledge, we were first to report a detailed characterization of neurovascular damage in the neonatal mouse retina after exposure to Rice-Vannucci HIE model. ${ }^{[15]} \mathrm{We}$ examined the effect of $\mathrm{HI}$ exposure of postnatal day 9 (P9) neonatal mice on retinal neurovascular integrity. ${ }^{[15]}$ The mouse retina, like in the human, has three layers of blood vessels. Our studies showed that blood vessels in different layers were either degenerated or failed to form. Similarly, our studies demonstrated that exposure to $\mathrm{HI}$ conditions induce neuronal degeneration and glial activation. Observed vascular and neuronal damages were irreversible and most noticeable in the periphery of the retina.

Ischemic stroke can also occur in juvenile humans and result in devastating and lasting disabilities including vision loss. We recently reported on the effect of $\mathrm{HI}$ exposure of juvenile mice (age 30 days) on the functional and structural integrity of the retinal blood vessels and neurons. ${ }^{[16]}$ These studies revealed that blood vessels were damaged and that structural and functional integrity of the neurons of the injured retinas were affected as the b-wave and the inner retinal layers were compromised.

Of note, we found retinal damage after exposure to $\mathrm{HI}$ vary among individuals; some show mild to no damage, some show moderate injuries, and others show severe injuries. Similar interindividual variabilities in the degree of damage after HIE exposure were reported in mouse, rat, and human neonatal brains ${ }^{[7,17-19]}$ and retina. ${ }^{[13,20-22]}$

It is unknown why different individuals respond differently after exposure to the same $\mathrm{HI}$ conditions. Maturation status of blood vessels 
and neurons could contribute to the severity of the damage after exposure to ischemic stroke. This is in line with the fact that we found the occurrence of severe retinal vascular damage to be much higher in neonates as compared with juvenile mice. Also, the magnitude of the severe damage was far more apparent and devastating in the neonate mice. Thus, age seems to play a significant role. It is also possible that variation in individual's hemodynamic properties could contribute to the HI-caused damage, ${ }^{[23]}$ since the vascular structure and hence hemodynamic properties varies among retinas. Also, retinas of male and female animals may show different severity of injuries after exposure to the same $\mathrm{HI}$ conditions, as in the brain. ${ }^{24,25]}$

Recent clinical studies have also demonstrated that $\mathrm{HIE}$ results in direct retinal damage in human neonates. At least $24.3 \%$ of eyes of newborns with a history of HIE were found to have retinal hemorrhage. ${ }^{[22,26]}$ An independent study examined the retinal integrity of two infants diagnosed with HIE using a handheld spectral domain optical coherence tomography (SD-OCT) imaging system. One infant with a history of moderate HIE was found to have severe retinal damage as manifested by thinning of all layers of the retina. The second infant with a history of severe HIE had subretinal fluid but without other obvious retinal damage. These findings support the notion that the retina is a prime target of $\mathrm{HI}$ insult, and the severity of retinal damage is independent of the severity of brain damage. A more recent report found three out of eight (37.5\%) examined infants with HIE to have various types of retinal damage, such as macular cystoid spaces, thinning in the retinal ganglion cell layer, acute middle maculopathy, and abnormally thin fovea. ${ }^{[20]}$

Preclinical studies including ours and recent human reports demonstrate that both neurons and blood vessels of the retina in neonates and juveniles are vulnerable to $\mathrm{HI}$ exposure. These findings call for more clinical attention in assessing the structural and functional integrity of retina of neonates and juvenile humans after exposure to hypoxic-ischemic insults or ischemic stroke. In addition, it is important to start effort in developing interventional methods to prevent and treat $\mathrm{HI}$-induced and ischemic stroke-induced retinal neurovascular damage. The underlying mechanisms that lead to damage of neurons and blood vessels in the retina after exposure to $\mathrm{HI}$ conditions remain unknown.

The activation of cell death in brain begins within the first 3-24 hr after exposure to $\mathrm{HI}$ conditions. ${ }^{[27]}$ It is likely that critical factors that are responsible for the neurovascular degeneration will be differentially expressed in the early stages of the response to the $\mathrm{HI}$ insult. Single cell-RNA sequencing (scRNA-Seq) method can be utilized to determine changes in the transcriptome profiles in the retina after the onset of the $\mathrm{HI}$ insult. Identification of altered genes/pathways known to be important for cell death, angiogenesis, and/or neurogenesis could provide more details regarding the underlying mechanisms. These pathways can be targeted for development of new therapeutics to preserve neurovascular functions not only in the brain but also in the retina.

\section{Financial Support and Sponsorship}

This work was supported in part by an unrestricted award from Research to Prevent Blindness to the Department of Ophthalmology and Visual Sciences; the Retina Research Foundation; NIH grants P30 EY016665, P30 CA014520, S10 OD018221, and EY026078. NS is a recipient of RPB Stein Innovation Award.

\section{Conflicts of Interest}

There is no conflict of interest.

\section{REFERENCES}

1. Douglas-Escobar M, Weiss MD. Hypoxic-ischemic encephalopathy: a review for the clinician. JAMA Pediatr 2015;169:397-403.

2. Cioni G, Bertuccelli B, Boldrini A, Canapicchi R, Fazzi B, Guzzetta A, et al. Correlation between visual function, neurodevelopmental outcome, and magnetic resonance imaging findings in infants with periventricular leucomalacia. Arch Dis Child Fetal Neonatal Ed 2000;82:F134-F140.

3. McCulloch DL, Taylor MJ, Whyte HE. Visual evoked potentials and visual prognosis following perinatal asphyxia. Arch Ophthalmol 1991;109:229-233.

4. Hoyt CS. Brain injury and the eye. Eye 2007;21:1285-1289.

5. Sheldon RA, Sedik C, Ferriero DM. Strain-related brain injury in neonatal mice subjected to hypoxia-ischemia. Brain Res 1998;810:114-122.

6. Cikla U, Chanana V, Kintner DB, Udho E, Eickhoff J, Sun $\mathrm{W}$, et al. ERalpha signaling is required for TrkB-mediated hippocampal neuroprotection in female neonatal mice after hypoxic ischemic encephalopathy(1,2,3). eNeuro 2016;3.

7. Rice JE 3rd, Vannucci RC, Brierley JB. The influence of immaturity on hypoxic-ischemic brain damage in the rat. Ann Neurol 1981;9:131-141. 
8. Vannucci RC, Vannucci SJ. A model of perinatal hypoxicischemic brain damage. Ann N Y Acad Sci 1997;835:234249.

9. Vannucci SJ, Seaman LB, Vannucci RC. Effects of hypoxiaischemia on GLUT1 and GLUT3 glucose transporters in immature rat brain. J Cereb Blood Flow Metab 1996;16:7781.

10. Vannucci RC, Vannucci SJ. Perinatal hypoxic-ischemic brain damage: evolution of an animal model. Dev Neurosci 2005;27:81-86.

11. Steck J, Blueml C, Kampmann S, Greene B, Maier RF, Arnhold S, et al. Retinal vessel pathologies in a rat model of periventricular leukomalacia: a new model for retinopathy of prematurity? Invest Ophthalmol Vis Sci 2015;56:18301841.

12. Huang HM, Huang CC, Hung PL, Chang YC. Hypoxicischemic retinal injury in rat pups. Pediatr Res 2012;72:224-231.

13. Jung S, Polosa A, Lachapelle P, Wintermark P. Visual impairments following term neonatal encephalopathy: do retinal impairments also play a role? Invest Ophthalmol Vis Sci 2015;56:5182-5193.

14. Tam SJ, Watts RJ. Connecting vascular and nervous system development: angiogenesis and the blood-brain barrier. Annu Rev Neurosci 2010;33:379-408.

15. Zaitoun IS, Cikla U, Zafer D, Udho E, Almomani R, Suscha $A$, et al. Attenuation of retinal vascular development in neonatal mice subjected to hypoxic-ischemic encephalopathy. Sci Rep 2018;8:9166.

16. Zaitoun I, Shahi P, Suscha A, Chan K, GJ M, BR P, et al. Hypoxic-ischemic injury causes functional and structural neurovascular degeneration in the Juvenile mouse retina. Sci Rep 2021; 11(1):12670.

17. Nair J, Kumar VHS. Current and Emerging therapies in the management of hypoxic ischemic encephalopathy in neonates. Children 2018;5:99.

18. Cengiz P, Uluc K, Kendigelen P, Akture E, Hutchinson E, Song $\mathrm{C}$, et al. Chronic neurological deficits in mice after

Correspondence to:

Ismail Zaitoun, PhD. Department of Ophthalmology and Visual Sciences, University of Wisconsin School of Medicine and Public Health, 1111 Highland Ave., WIMR 9418, Madison, WI 53705, USA.

E-mail: iszaitoun@wisc.edu

Received: 07-05-2021 Accepted: 01-06-2021

$$
\text { Access this article online }
$$

Website: https://knepublishing.com/index.php/JOVR

DOI: 10.18502/jovr.v16i3.9427 perinatal hypoxia and ischemia correlate with hemispheric tissue loss and white matter injury detected by MRI. Dev Neurosci 2011;33:270-279.

19. Ferriero DM, Miller SP. Imaging selective vulnerability in the developing nervous system. J Anat 2010;217:429435.

20. Mangalesh S, Tran-Viet D, Pizoli C, Tai V, El-Dairi MA, Chen $X$, et al. Subclinical retinal versus brain findings in infants with hypoxic ischemic encephalopathy. Graefes Arch Clin Exp Ophthalmol 2020;258:2039-2049.

21. Tran-Viet D, Wong BM, Mangalesh S, Maldonado R, Cotten $\mathrm{CM}$, Toth CA. Handheld spectral domain optical coherence tomography imaging through the undilated pupil in infants born preterm or with hypoxic injury or hydrocephalus. Retina 2018;38:1588-1594.

22. Akin MA, Sahin O, Cansever M, Sirakaya E, Robertson NJ. Early retinal findings following cooling in neonatal encephalopathy. Neuropediatrics 2019;50:15-21.

23. Charriaut-Marlangue C, Bonnin P, Leger PL, Renolleau $\mathrm{S}$. Brief update on hemodynamic responses in animal models of neonatal stroke and hypoxia-ischemia. Exp Neurol 2013;248:316-320.

24. Vannucci SJ, Hurn PD. Gender differences in pediatric stroke: is elevated testosterone a risk factor for boys? Ann Neurol 2009;66:713-714.

25. Hill CA, Fitch RH. Sex differences in mechanisms and outcome of neonatal hypoxia-ischemia in rodent models: implications for sex-specific neuroprotection in clinical neonatal practice. Neurol Res Int 2012;2012:867531.

26. Eris E, Eris D, Seymen Z, Karasu B, Dıracoglu A, Perente $I$, et al. Retinal haemorrhage rates and resolution time of retinal haemorrhage in newborns after hypothermic treatment for hypoxic-ischemic encephalopathy. Arch Pediatr 2020;27:29-32.

27. Thornton C, Leaw B, Mallard C, Nair S, Jinnai M, Hagberg $\mathrm{H}$. Cell death in the developing brain after hypoxiaischemia. Front Cell Neurosci 2017;11:248.

This is an open access journal, and articles are distributed under the terms of the Creative Commons Attribution-NonCommercial-ShareAlike 4.0 License, which allows others to remix, tweak, and build upon the work non-commercially, as long as appropriate credit is given and the new creations are licensed under the identical terms.

How to cite this article: Zaitoun IS, Sheibani N. Hypoxic-Ischemic Encephalopathy: Impact on Retinal Neurovascular Integrity and Function. J Ophthalmic Vis Res 2021;16:317-319. 